\title{
Resource planning for risk diversification in the formation of a digital twin enterprise
}

\author{
A.V. Liezina ${ }^{a}$, K. A. Andriushchenko ${ }^{b^{*}}$, O. D. Rozhko ${ }^{c}$, O. I. Datsii ${ }^{d}$, L. O. Mishchenko and O. O. \\ Cherniaieva $^{\mathrm{f}}$
} aDepartment of Management, Faculty of Economics and Management, SHEE "Kyiv National Economic University named after Vadym Hetman”,
Ukraine
${ }^{b}$ Department of Economics and Entrepreneurship, Faculty of Economics and Management, SHEE «Kyiv National Economic University named after
Vadym Hetman», Ukraine
${ }^{c}$ Taras Shevchenko National University of Kyiv, Vice-rector for scientific and pedagogical work, Ukraine
${ }^{d}$ Head of the Department of Finance, Educational and Scientific Institute of Management, Economics and Finance, Banking and Insurance of the
Interregional Academy of Personnel Management, Ukraine
${ }^{e}$ Department of State, Local and Corporate Finance, Faculty of Finance, University of Customs and Finance, Ukraine
${ }^{f}$ Department of Economics and Business Management, Educational and Scientific Institute of Management, Economics and Finance, Interregional
Academy of Personnel Management, Ukraine

\section{H R O N I C L E}

\section{Article history:}

Received: April 29, 2020

Received in revised format:

July 302020

Accepted: August 10, 2020

Available online:

August 17, 2020

Keywords:

Digital twin

Resource planning

Stochastic uncertainty

Risk diversification

Investment portfolio

Digital twin prototypes

Digital twin instances

Digital twin life cycle

\section{A B S T R A C T}

\begin{abstract}
Recently, there has been explosive growth in the development of the digital industry concept. One of the most important elements of this concept is the application of mathematical modeling methods and data mining to create models of production processes and final products, with the aim of making decisions under stochastic uncertainty. In this paper, a method of diversifying the investment portfolio in the formation of a digital twin is proposed, which is aimed at reducing the total risk by distributing existing assets (resources, investments, etc.) between the analog and digital enterprises. Three types of scenario are proposed: pessimistic - when an enterprise - a pessimist - does not show risk exposure under this scenario when forming a digital counterpart; neutral - when an enterprise shows a neutral attitude to risk (indifference); optimistic - enterprise - optimist is exposed to risk, in particular the risk of untapped opportunities. The result is a set of optimal portfolios, each reflecting a particular position of the enterprise on the risks of untapped opportunities and a certain scenario of forming a portfolio structure, taking into account the relationship between the individual components of the risks of untapped opportunities. Highlighted the advantages of technology "digital twins" for business. Digital counterparts use the data obtained from sensors installed on production lines or on the basis of the final product to predict equipment malfunctions, optimize product quality and reduce the negative impact of production processes on the environment.
\end{abstract}

\section{Introduction}

At the present stage of global development, the leading countries of the world have entered the phase of formation of the economy of the fourth industrial revolution in the format of the digital economy (Schwab, 2017; Podvoiskii, 2016). This means that the global economy will change dramatically over the next 10-15 years. These are not the forecasts of futurologists, but a consequence of the processes of introducing new technologies that are already happening today. Under the influence of a powerful wave of a new industrial revolution, a structural restructuring of the foundations of many sectors of the economy takes

* Corresponding author

E-mail address: katya373@i.ua (K. A. Andriushchenko) 
place, it breaks down the barriers between sectors and the borders between suppliers, producers and consumers. The fundamental difference between the modern process of digital transformation and previous industrial revolutions is that they were caused by technological progress, which initially affected only production, while current changes simultaneously affect both consumers and manufacturers and suppliers. Another distinctive feature of modern changes is that previous industrial revolutions spurred the demand for many resources, and the current one is aimed at reducing resource intensity. The concept of the digital industry involves the organization of production processes using intelligent software platforms that collect, store and process data from sensor networks, using data mining and machine learning methods to increase production efficiency (Kupriyanovskii et al., 2016). Among the initiatives to develop this concept, we can single out the Industry 4.0 program (Derby, 2017) developed in Germany, the Coalition of Smart Production Leaders (Tikhanychev, 2017) in the USA and the concept of the industrial Internet of Things proposed by General Electric Corporation (Jenster et al., 2016). One of the key approaches that unite these programs is the concept of digital twins (DD), which provides the creation and support of virtual models of real equipment, industrial processes and final products. According to (Tolstykh, 2017), DD is an integrated multi-physical, multi-scale probabilistic simulation of a complex product that uses the most suitable physical models, relevant sensor data, etc. in order to obtain the most reliable representation of the corresponding real object. The emergence of "digital twins" was the logical result of the development of the concept of "digital production" and the Industrial Internet of Things (see fig. 1). This concept first appeared in 2003 after the publication of an article by the professor of the University of Technology of Florida Michael Greaves, "Digital twins: excellence in production based on a virtual prototype of a plant" (Michael, 2014).

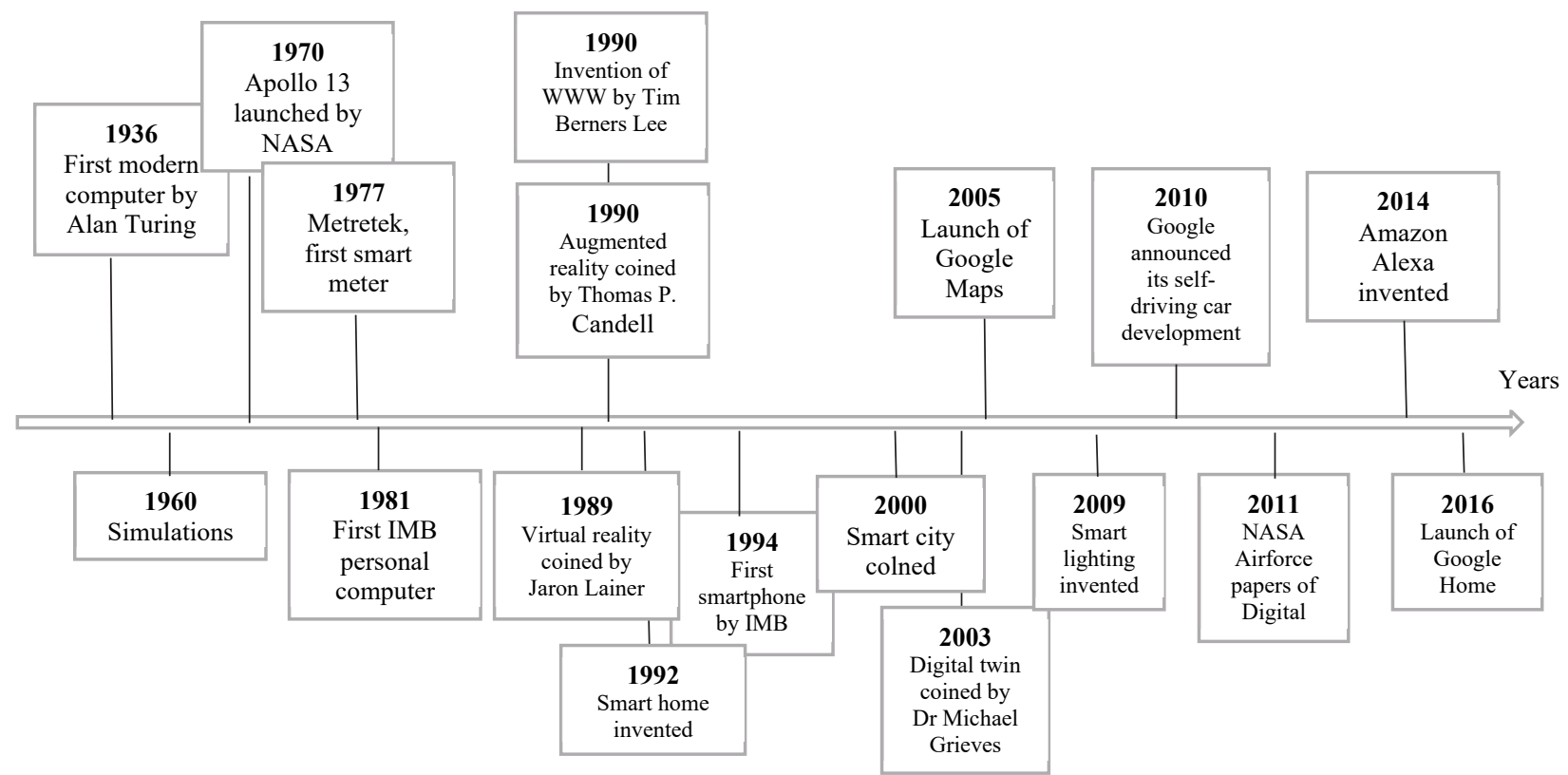

Fig. 1. The evolution of digital transformation and the development of digital twins

Many industries are currently collecting equipment performance data. In recent years, digital transformation has been able not only to fully process the collected information using advanced analytics, but also to make informed decisions to optimize operations in various industries. Similarly, new modelling technologies enable manufacturers to use digital counterparts in their products and processes. New projects can be tested in the virtual world, which leads to saving time, money and resources. A digital twin can enable companies to solve physical problems faster by detecting them with a much higher degree of accuracy, design and create better products and, ultimately, better serve their customers. With this type of smart architectural design, companies can realize value and benefits interactively and faster than ever before (Michael, 2014).

\section{Literature Survey}

There are many definitions of a digital twin. We will consider some of them in our work. Glaessgen \& Stargel (2012), in his work, defines a digital twin as an integrated multiphysical, multiscale, probabilistic simulation of an assembled vehicle or system that uses the best available physical models, sensor updates, history, etc. Lee et al. (2013) consider the digital twin as a unified model of a real machine that runs on a cloud platform and simulates a state of health with integrated knowledge from both datadriven analytical algorithms and other available physical knowledge. El Saddik (2018) focuses on the fact that a digital twin is a digital copy of an animate or inanimate physical entity. Connecting the physical and virtual worlds, data is transmitted seamlessly, allowing the virtual entity to exist simultaneously with the physical entity. Soderberg et al. (2017) in their work describe a digital twin as a digital copy of a physical system for real-time optimization. Bolton et al. (2018) describe a digital 
twin as a dynamic virtual representation of a physical object or system throughout its entire life cycle using real-time data for understanding, study, and reasoning. The authors of Tao, Sui, Liu, Qi, Zhang, Song, Guo, Lu \& Nee (2018) describe the digital twin as the ability to actually display all components in the product life cycle using physical data, virtual data and the interaction data between them. In his work, Ponsard (2018) describes the experience of using a digital twin with a steel mill, where an analog enterprise uses a digital twin in part and only on a temporary basis. Verriet et al. (2018) described how Philips Lighting uses the digital twin to formulate its main product, the lighting system in the enterprise, as well as the interaction of this system with other technological components of the organization. Felix Strohmeier et al. (2018) described the operational activities (industrial assets) of a digital twin that collects, tracks and analyzes operational cycle data to further improve operations, determine maintenance, and formulate long-term strategies for using enterprise assets. The authors by Van Kruijsdijk (2018), who described the work of a digital twin in chemical plants and offshore platforms (Shell), continued their studies in articles in this field, where he studied the impact and improvement of work, as well as the maintenance and safety of analog enterprises. In the work by Stefan Boschert and Roland Rosen (2018) on the example of railway rail switches, they emphasized that their maintenance is crucial for ensuring safety and smooth operation. In this case, the function of the digital twin was to identify failures before they became critical, as well as to determine the general methodology for obtaining the necessary information and making decisions in emergency situations. In the work by Zavodsky (2018) considered an example of the company Insilico, which describes the creation of a digital twin, which helps to predict the outcome of a particular disease, as well as the possibility of making decisions during the course of treatment with the ability to track and adjust throughout the process. The topic of safety and protection is considered in the article Damjanovic-Behrendt (2018), which turns its attention to the Smart Automotive sector, where strategic alliances between manufacturers complicate the development of research areas and their access to the market. Therefore, the company is developing an open source digital twin using machine learning capabilities to analyze behavior and predict security and privacy measures. All the works that we analyzed have one key drawback; they do not contain methods and approaches involving stochastic uncertainty. Stochastic uncertainty is a typical decision-making situation in technology and economics. In order to make a decision under the condition of stochastic uncertainty, we proposed an improved model with the possibility of using a mathematical apparatus.

\section{Methods}

Digital twins use various approaches for modeling real objects and technological processes, including statistical and data mining methods, computational modeling methods such as finite element method, etc. Each of these methods makes special demands on the necessary computing resources. For example, data mining methods require large-capacity storages with high throughput for collecting and accessing analytical data, and it is also necessary to ensure high scalability of the computing system for processing them; for the application of machine learning methods, nodes with installed accelerators are required, and for models using the finite element method, high CPU performance and large amounts of RAM are required. The recognition of the portfolio of diversification with digital form is straightened out for the lower quality of the portfolio with the help of active assets (resources, investment) and the development of analog and digital devices. In evaluating the situation for intelligence and risk business, it's important to undo sub 'activism. When I take the most valuable portfolio "in the portfolio", you can place the form of the shutter (the function or the non-property) of the business when formulating the digital door to the open warehouse. Let the available resource $C$ be distributed between the analogy enterprise and the digital copy: $\mathrm{c}=\sum_{i}^{n} c_{i}$. We introduce a set of variables $\mathrm{X}=\left\{\mathrm{x}_{\mathrm{i}}\right\}, i=\overline{1, n}: x_{i} \geq 0, x_{i}=\frac{c_{i}}{c}, \sum_{i=1}^{n} x_{i}=1$. We will form a portfolio of $\mathrm{n}$ assets on a plural of alternatives $\mathrm{A}=$ $\left\{\mathrm{a}_{\mathrm{i}}\right\}, i=\overline{1, n}$. Each of the options $\mathrm{a}_{\mathrm{i}}, i=\overline{1, n}$ we will characterize the probabilities of losing $P_{I}$, and winnings $S_{I}$, respectively: $\mathrm{A}=\left\{\mathrm{a}_{\mathrm{i}}\left(\mathrm{p}_{\mathrm{i}}, \mathrm{s}_{\mathrm{i}}\right)\right\}, i=\overline{1, n}$. We set the ratio of probabilities $p, s$ for options $\mathrm{a}_{\mathrm{i}}, i=\overline{1, n}$ by the conditions

$$
p_{1}<\ldots \ldots, p_{i}, \ldots \ldots<p_{n}, s_{1}<\ldots \ldots, s_{i}, \ldots . .<s_{n}, p_{i}<s_{i}
$$

We will consider such resource $C$ allocation effective. Let the plural of alternatives $\mathrm{A}=\left\{\mathrm{a}_{\mathrm{i}}\right\}, i=\overline{1, n}$ form some portfolio $e k \epsilon$ $E\{e k\}, k=\overline{1, \infty}$, of components with the corresponding shares $\left\{\mathrm{x}_{\mathrm{k}, \mathrm{j}}\right\}: \mathrm{e}_{\mathrm{k}}=\left\{\mathrm{x}_{\mathrm{k}, \mathrm{j}}\right\}, \sum_{i=1}^{n} x_{k, i}=1, x_{k, i} \geq 0, i=\overline{1, n}$.

The choice of the best (optimal) decision $d_{o p t}$ on the formation of the portfolio will be done by the rule:

$$
d_{o p t}=\left\{e_{k, o p t} \mid e_{k, o p t} \in E \wedge r_{k, o p t}=\min \left(r_{k}\right)\right\}
$$

where $r_{k}$ - the total risk of the portfolio.

Consider the case $\mathrm{c}=\mathrm{c}_{1}+\mathrm{c}_{2}$ and two scenarios of enterprise behavior when creating a digital counterpart through the formation of type portfolios $\left\{\mathrm{x}_{1}, \mathrm{x}_{2}\right\}$ of $A=\left\{\mathrm{a}_{1}, \mathrm{a}_{2}\right\}$ :

The pessimistic scenario under which the decision carrier seeks to increase the proportion of $\mathrm{x}_{1}$ in the portfolio; let this scenario be characterized by the fact that the enterprise operates by limiting itself $x_{1} \geq 0,5 ; x_{2} \leq 0,5 ; x_{1}+x_{2}=1$;

The optimistic scenario in which the solution carrier seeks to increase the proportion of $\mathrm{x}_{2}$ in the portfolio; this scenario is characterized by the fact that the enterprise operates under restrictions $x_{1} \leq 0,5 ; x_{2} \geq 0,5 ; x_{1}+x_{2}=1$. 
The aggregate risk $\mathrm{r}\left(\mathrm{x}_{1}, \mathrm{x}_{2}\right)$ of the portfolio $\left\{\mathrm{x}_{1}, \mathrm{x}_{2}\right\}$, taking into account the risk of unused opportunities, is written in the form:

$r\left(x_{1}, x_{2}\right)=p_{1} x_{1}+p_{2} x_{2}+s_{2}\left(1-p_{2}\right) x_{1}+s_{1}\left(1-p_{1}\right) x_{2}$

For example, let's have the following data on the probabilities of portfolio losses and gains $\left\{\mathrm{x}_{1}, \mathrm{x}_{2}\right\}: \mathrm{p}_{1}=0,005 ; \mathrm{p}_{2}=0,02 ; \mathrm{s}_{1}=$ $0.008, \mathrm{~s}_{2}=0.025$. The aggregate risk of the portfolio $\left\{\mathrm{x}_{1}, \mathrm{x}_{2}\right\}$ according to formula (3) will be

$r\left(x_{1}, x_{2}\right)=0,0295 x_{1}+0,02796 x_{2}$

Solving the problem of linear programming for the pessimistic scenario of digital counterpart formation, we obtain the optimal distribution $\mathrm{x}_{1}=0,5 ; \mathrm{x}_{2}=0,5$. The aggregate risk of loss of the optimal portfolio $\left\{\mathrm{x}_{1}, \mathrm{x}_{2}\right\}$ will be $r\left(c, x_{1}, x_{2}\right)=0,02873 c$. Let's expand the problem of diversification of aggregate risk in case $\mathrm{c}=\mathrm{c}_{1}+\mathrm{c}_{2}+\mathrm{c}_{3}$ of formation of type portfolios $\left\{\mathrm{x}_{1}, \mathrm{x}_{2}, \mathrm{x}_{3}\right\}$ and set three scenarios of formation of a digital twin (depending on their assessment of the situation):

1) Pessimistic - when an enterprise - a pessimist - does not show risk aversion; under this scenario, the company will try to increase the share of $\mathrm{x}_{1}$ in each portfolio by forming a digital twin, focusing on the limitation of the form $\mathrm{x}_{1} \geq 1 / 3$;

2) Neutral - when an enterprise shows a neutral attitude to risk (indifference); let the enterprise take the lead when forming a digital counterpart in this scenario $\mathrm{a}_{2}$ at $\mathrm{x}_{2} \geq 1 / 3$;

3) Optimistic - enterprise - optimist - shows a tendency to risk, in particular to the risk of unused opportunities; let in this scenario, the enterprise in the formation of a digital twins focuses on the limitation of the species.

Then, there are four possible forms of aggregate risk $r\left(x_{1}\right)$ for type of portfolios $\left(\mathrm{x}_{1}, \mathrm{x}_{2}, \mathrm{x}_{3}\right)(1)$ generated by the scenario 1

$$
\begin{aligned}
& r_{1}\left(x_{1}, x_{2}, x_{3}\right)_{(1)}=l\left(x_{1}, x_{2}, x_{3}\right)+s_{1}\left(1-p_{1}\right)\left(x_{2}+x_{3}\right)+s_{2}\left(1-p_{2}\right) x_{1} \\
& r_{2}\left(x_{1}, x_{2}, x_{3}\right)_{(1)}=l\left(x_{1}, x_{2}, x_{3}\right)+s_{1}\left(1-p_{1}\right) x_{2}++s_{2}\left(1-p_{2}\right)\left(x_{1}+x_{3}\right) \\
& r_{3}\left(x_{1}, x_{2}, x_{3}\right)_{(1)}=l\left(x_{1}, x_{2}, x_{3}\right)+s_{1}\left(1-p_{1}\right)\left(x_{2}+x_{3}\right)+s_{3}\left(1-p_{3}\right) x_{1} \\
& r_{4}\left(x_{1}, x_{2}, x_{3}\right)_{(1)}=l\left(x_{1}, x_{2}, x_{3}\right)+s_{1}\left(1-p_{1}\right) x_{2}+s_{2}\left(1-p_{2}\right) x_{3}+s_{3}\left(1-p_{3}\right) x_{1}
\end{aligned}
$$

where $l\left(x_{1}, x_{2}, x_{3}\right)-p_{1} x_{1}+p_{2} x_{2}+p_{3} x_{3}$.

In formulas (5) - (8), additional $l\left(x_{1}, x_{2}, x_{3}\right)$ components of aggregate risk $r_{1}\left(x_{1}, x_{2}, x_{3}\right)_{(1)}$ determine different options for accounting for unused opportunities by an enterprise pessimist. With the neutral (2) scenario of portfolio formation $\left(x_{1}, x_{2}, x_{3}\right)_{(2)}$ we get two forms of aggregate risk recording:

$$
\begin{aligned}
& r_{5}\left(x_{1}, x_{2}, x_{3}\right)_{(2)}=l\left(x_{1}, x_{2}, x_{3}\right)+s_{2}\left(1-p_{2}\right)\left(x_{1}+x_{3}\right)+s_{3}\left(1-p_{3}\right) x_{2} \\
& r_{6}\left(x_{1}, x_{2}, x_{3}\right)_{(2)}=l\left(x_{1}, x_{2}, x_{3}\right)+s_{2}\left(1-p_{2}\right)\left(x_{1}+x_{3}\right)+s_{1}\left(1-p_{1}\right) x_{2}
\end{aligned}
$$

In all cases $l\left(x_{1}, x_{2}, x_{3}\right)=p_{1} x_{1}+p_{2} x_{2}+p_{3} x_{3}$.

In an optimistic (3) scenario, there are three forms of aggregate risk recording:

$$
\begin{aligned}
& r_{7}\left(x_{1}, x_{2}, x_{3}\right)_{(3)}=l\left(x_{1}, x_{2}, x_{3}\right)+s_{3}\left(1-p_{3}\right)\left(x_{1}+x_{2}\right)+s_{2}\left(1-p_{2}\right) x_{3} \\
& r_{8}\left(x_{1}, x_{2}, x_{3}\right)_{(3)}=l\left(x_{1}, x_{2}, x_{3}\right)+s_{2}\left(1-p_{2}\right)\left(x_{1}+x_{3}\right)+s_{3}\left(1-p_{3}\right) x_{2} \\
& r_{8}\left(x_{1}, x_{2}, x_{3}\right)_{(1)}=l\left(x_{1}, x_{2}, x_{3}\right)+s_{2}\left(1-p_{2}\right) x_{1}+s_{3}\left(1-p_{3}\right) x_{2}+s_{1}\left(1-p_{1}\right) x_{3}
\end{aligned}
$$

The result is a set of optimal portfolios, each reflecting a particular position of the enterprise on the risks of untapped opportunities and a certain scenario of forming a portfolio structure, taking into account the relationship between the individual components of the risks of untapped opportunities.

\section{Results}

In the implementation of each of the scenarios $(1,2,3)$, the enterprise may also choose one of three portfolio formation strategies, increasing the corresponding proportion of $x$, at the expense of other components:

1) uniformly reducing the share of alternatives;

2) maximizing the share of less risky alternatives;

3) maximizing the share of more risky alternatives.

Below is an example of solving the problem of forming the optimal structure of the investment program of enterprise development in the formation of a digital counterpart in order to diversify portfolio risk. The following three areas of investment in the enterprise were considered when forming a digital twin, identified as alternatives:

$a_{1}$ - providing the necessary level of reliability of the digital duplicate with the equipment and safety of the existing equipment, as well as in order to prevent power losses due to wear and tear;

$a_{2}$ - completion of the started objects of construction or conversion of existing equipment of the enterprise for transformation of an analogy enterprise and formation of a digital twin;

$a_{3}$ - implementation of promising projects that maximize the assets of the company when forming a digital twin in the long run/ 
The calculations were made for such probabilities of portfolio losses and gains $\left(x_{1}, x_{2}, x_{3}\right): p_{1}=0,005, p_{2}=0,02, p_{3}=0,035 ; s_{1}=$ $0.008, s_{2}=0.025, s_{3}=0.035$. The optimal structure of the investment program was selected based on the pessimistic scenario for the event of portfolio formation $\left(x_{1}, x_{2}, x_{3}\right)_{(I)}$ the aggregate risk of which, according to the formula (5) will be:

$r\left(x_{1}, x_{2}, x_{3}\right)_{(1)}=0,0295 x_{1}+0,02796 x_{2}+0,04296 x_{3}$

Herewith were considered the strategies:

1) an increase in the proportion of $x_{1}$ due to the uniform reduction of particles $x_{2}, x_{3}$;

2) increase $x_{1}$ by reducing $x_{2}, x_{3}$, but at the same time maintaining the particles $x_{2}$;

3 ) increase $x_{1}$ due to $x_{2}, x_{3}$, but with the preservation of the fraction $x_{3}$.

The results for finding the best options are summarized in Tables 1-3.

Table 1

Fragment of the decision table in forming the optimal structure of the investment program (strategy 1)

\begin{tabular}{cccc}
\hline & Portions in the portfolio $\left(x_{1}, x_{2}, x_{3}\right)_{(1)}$ & & Aggregate risk \\
\hline$X_{1}$ & $X_{2}$ & $X_{3}$ & $r_{l}\left(x_{1}, x_{2}, x_{3}\right)_{(1)}$ \\
\hline 0,633333 & 0,183333 & 0,183333 & 0,031685 \\
0,683333 & 0,153333 & 0,153333 & 0,031387 \\
0,733333 & 0,133333 & 0,133333 & 0,031089 \\
0,783333 & 0,108333 & 0,108333 & 0,030791 \\
0,833333 & 0,083333 & 0,083333 & 0,030493 \\
0,883333 & 0,058333 & 0,058333 & 0,030195 \\
0,933333 & 0,033333 & 0,033333 & 0,029897 \\
0,983333 & 0,008333 & 0,008333 & $\mathbf{0}$ \\
$\mathbf{1}$ & $\mathbf{0}$ & $\mathbf{0}$ & $\mathbf{0 2 9 5 0 0}$ \\
\hline
\end{tabular}

Table 2

Fragment of the decision table in forming the optimal structure of the investment program (strategy 2)

\begin{tabular}{|c|c|c|c|}
\hline \multicolumn{3}{|c|}{ Portions in the portfolio $\left(x_{1}, x_{2}, x_{3}\right)_{(1)}$} & \multirow{2}{*}{$\begin{array}{l}\text { Aggregate risk } \\
r_{1}\left(x_{1}, x_{2}, x_{3}\right)_{(1)}\end{array}$} \\
\hline$X_{1}$ & $X_{2}$ & $X_{3}$ & \\
\hline 0,633333 & 0,333333 & 0,033333 & 0,029735 \\
\hline 0,683333 & 0,316667 & 0 & 0,029012 \\
\hline 0,733333 & 0,266667 & 0 & 0,029089 \\
\hline 0,783333 & 0,216667 & 0 & 0,029166 \\
\hline 0,833333 & 0,166667 & 0 & 0,029243 \\
\hline 0,883333 & 0,116667 & 0 & 0,02932 \\
\hline 0,933333 & 0,066667 & 0 & 0,029397 \\
\hline 0,983333 & 0,016667 & 0 & 0,029474 \\
\hline 1 & 0 & 0 & 0,0295 \\
\hline
\end{tabular}

Table 3

Fragment of the decision table in forming the optimal structure of the investment program (strategy 3 )

\begin{tabular}{|c|c|c|c|}
\hline \multicolumn{3}{|c|}{ Portions in the portfolio $\left(x_{1}, x_{2}, x_{3}\right)_{(1)}$} & Aggregate risk \\
\hline$X_{1}$ & $X_{2}$ & $X_{3}$ & $r_{1}\left(x_{1}, x_{2}, x_{3}\right)_{(1)}$ \\
\hline 0,633333 & 0,333333 & 0,333333 & 0,0339353 \\
\hline 0,683333 & 0 & 0,316667 & 0,0337623 \\
\hline 0,733333 & 0 & 0,266667 & 0,0330893 \\
\hline 0,783333 & 0 & 0,216667 & 0,0324163 \\
\hline 0,833333 & 0 & 0,166667 & 0,0317433 \\
\hline 0,883333 & 0 & 0,116667 & 0,0310703 \\
\hline 0,933333 & 0 & 0,066667 & 0,0303973 \\
\hline 0,983333 & 0 & 0,016667 & 0,0297243 \\
\hline 1 & $\mathbf{0}$ & $\mathbf{0}$ & 0,0295000 \\
\hline
\end{tabular}

Thus, if we proceed from a pessimistic scenario, for a portfolio whose aggregate risk is written as (5) at specified probabilities of losses and gains for alternatives, the best option is the distribution of parts $\mathrm{x} 1=0,6833 ; \mathrm{x} 2=0,3167 ; \mathrm{x} 3=0$.

\section{Discussion}

A digital counterpart (sometimes also a "digital shadow") is a digital copy of real devices, processes, or even people. The overall idea is to build a digital partner throughout the life cycle of all actors involved. Digital twins are created entirely based on the specifications of their physical counterpart, whereby they document all changes and developments. To do this, digital twins require data derived from the history of a system or device, experts working in the field, and even data from other (third-party) organizations, processes, and systems (Andriushchenko, K., Kovtun, 2020). Thus, the digital twin can provide information and reports on the current state of its physical counterpart. Once configured, digital twins are used in various ways: a data processing tool (such as those generated by IoT devices), a model for executing calculations and scenarios that reduce the time and cost of 
product development and / or installation of complex systems, or a tool for providing ongoing review of systems that are often redistributed and used by multiple parties. Finally, given that digital twins can easily operate in isolated environments, they can be carefully analysed (for example, for security measures) without disrupting operating systems. In the future, they will be combined with other technologies, such as virtual reality or artificial intelligence, which will facilitate the search for digital twins and negate the validation of real devices or production processes (Andriushchenko \& Datsii, 2019). An example of an analogy and digital twin can be visualized in Fig. 2. The auxiliary components that go into the digital twin production process include the basic principles that can be applied in any digital twin configuration.

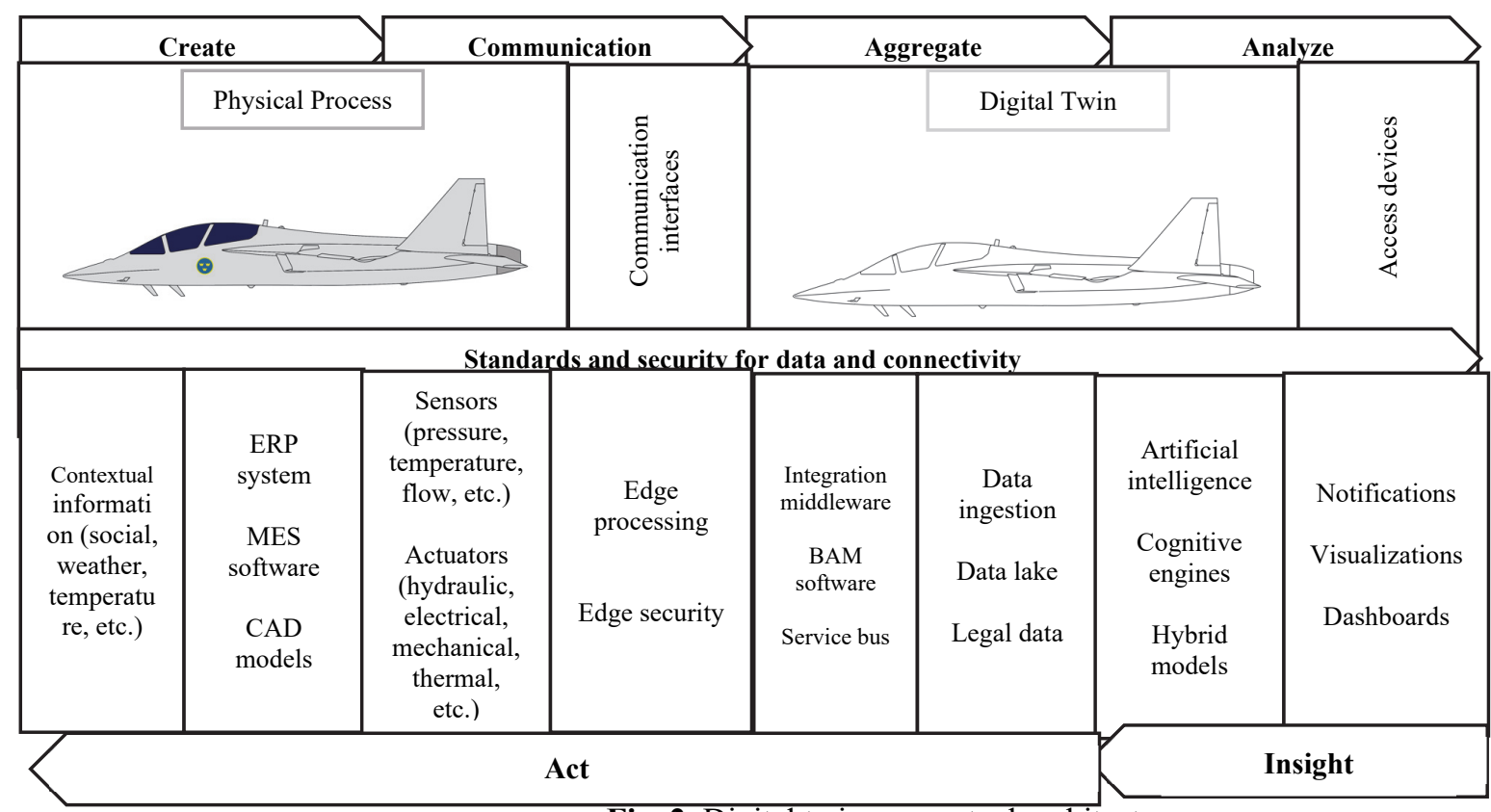

Fig. 2. Digital twin conceptual architecture

Source: Deloitte University Press

Among other things, it should be noted the advantages of the technology of creating "digital twins" for business. This is facilitated by the emergence of increasingly convenient and inexpensive tools for processing and storing big data. This fact has made it possible to increase the number of uses and opportunities for creating digital counterparts, which in turn adds value to the business. The main advantages of digital twins for business can be considered:

\section{Reduction of production costs}

As a rule, the product passes several tests before the final working prototype appears. This process is very expensive because it requires a significant investment of time and resources. Digital twins allow engineers to perform all tests and simulations in a virtual environment, reducing defects during actual production. In the digital world, it is much easier, cheaper and faster to repair defects than in the real world (Kovtun \& Andriushchenko, 2020). Digital analogues can eliminate almost all risks of future product launch and make sure that the physical object will work correctly. Therefore, one of the major benefits of digital counterparts is to reduce costs during production and maintenance.

\section{Reduced time to market}

The key to success of each company is the faster release of the product on the market. But often this is a problem because of the long iterations and constant improvements. When a company uses virtual counterparts to create a product or service, it significantly shortens the time to market because the product lifecycle is performed in a digital environment where all improvements can be made much faster and easier. The virtual prototype checks how its physical copy will behave, thereby optimizing development efficiency and time. Thus, the product can go on sale as soon as its production begins.

\section{Predicted diagnostic maintenance}

Another major benefit of the digital counterpart is that it can solve many problems in advance. This capability is called predicted service. Virtual copies constantly remotely control their physical prototypes, collecting various status information using sensors. The analysis of the collected data allows to predict possible breakdowns (Romanenko \& Chaplay, 2016).

Fig. 3 shows the cost of changing the design of a product using a digital twin, as well as showing a traditional approach to product development. 


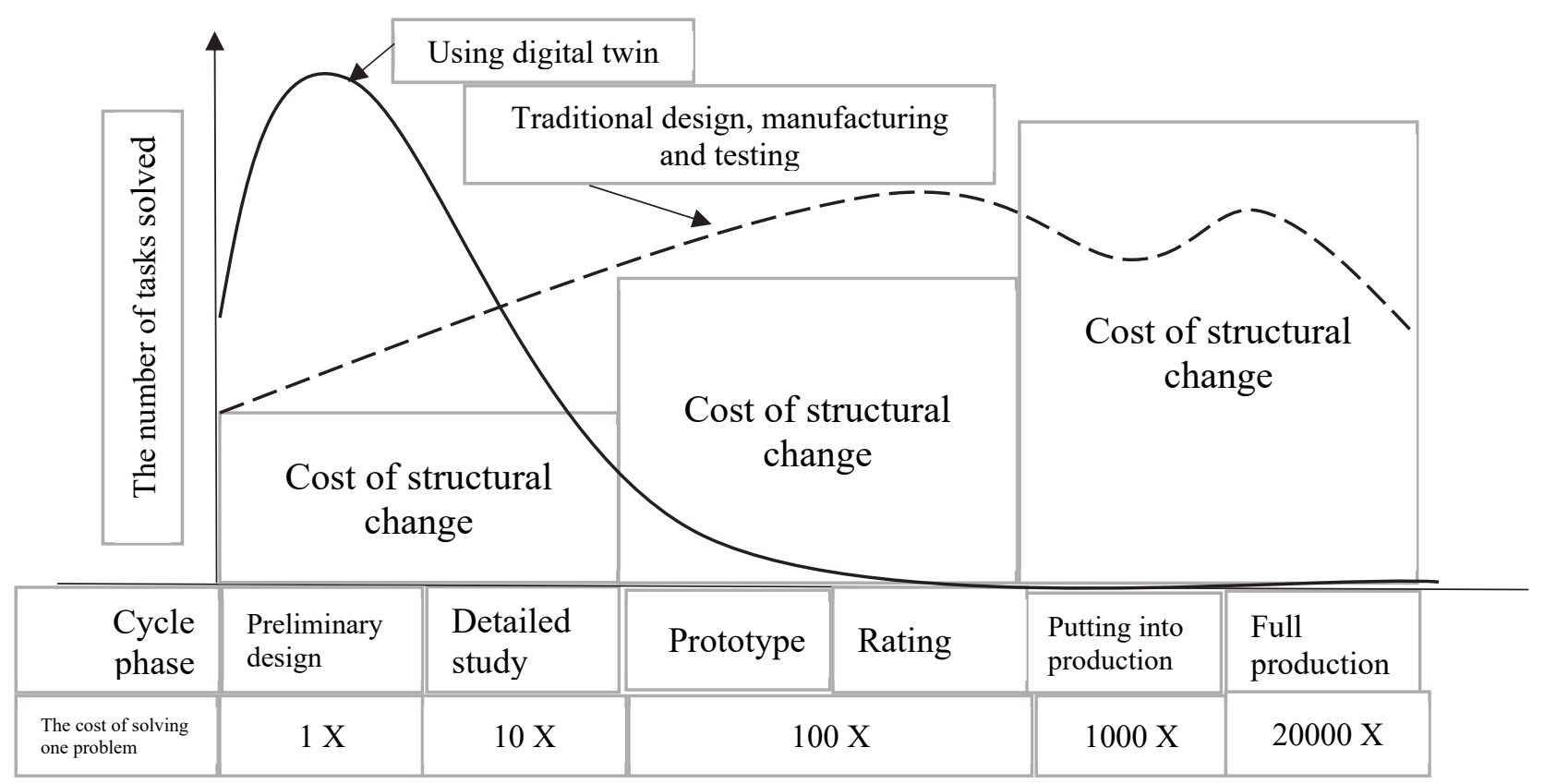

Fig. 3. Cost of product change using a digital twin

It can be seen from the figure that the use of a digital twin will allow to solve many problems of changing the product at the stage of "preliminary design" and "detailed elaboration". The cost of solving one problem at these stages is less than the cost of solving the problem at the stages of the prototype and evaluation, which is significantly less than the cost of solving the problem at the stages of production and full production. Thus, digital counterparts significantly reduce the company's cost of developing a new product. It should also be noted the terms "digital twin prototypes" (DTP) and "digital twin instances" (DTI), which were introduced in order to distinguish between the nature and purpose of digital counterparts (Andriushchenko \& Lavruk, 2019). In the early stages of the life cycle, DT consists mainly of artifacts used to optimize product functionality. Digital models are used to verify design options and to verify product functionality against its requirements using virtual prototypes (Digital Twin prototype). This approach greatly reduces time and costs when developing a new product. On the other hand, DTI emphasizes the aspect that with each individual physical object (digital) information is also collected throughout the entire life cycle. This does not have to be a restriction on the data of sensors and how to work with them, but may also include information from its production (for example, a supplier or a production line). With the ubiquitous appearance of sensors, a huge amount of data is available to communicate with DTI. In addition, since DTP focuses on the overall behavior of an object, it can be considered as a common part of each DTI and can be used to create solutions. Models included in DTP are usually created for very specific design issues. Thus, for the same component, as a rule, many different models are available, each of which represents its own design question regarding the corresponding model detailing. Modern PLM systems help archive and track these models. However, at the development stage, a huge number of models are created and even more data arrives, the sum of which cannot be saved, which needs to be done. The omission of this makes it difficult to derive new models for the latest applications, which is associated with the operation phase. Because information about limitations, assumptions, and underlying ideas on existing models is probably no longer available. On the other hand, in many cases it is already foreseen which particular questions will be asked during the operation phase of the product or, in other words, what functionality the digital twin of the product should provide during the operational phase. Therefore, it is advisable to design these digital twin functions in parallel with the product.

\section{Conclusions}

The digital twin is based on big data that comes in real time across multiple dimensions. These measurements can create an evolving profile of an object or process in the digital world that can provide important information about system performance, which will lead to decisions in the physical world, such as changes in product design and manufacturing processes. The digital twin is different from the traditional computer aided design (CAD) system and is not just another solution with IoT sensors. A digital twin is much more than any CAD system that is fully encapsulated in a computer environment that has demonstrated success in modeling complex environments. It can also be a more complex system than IoT systems that measure things such as position and diagnostics for the entire component, but not in the interaction between components and the processes of the entire product life cycle (Andriushchenko \& Buriachenko, 2020). So, the use of a digital twin will allow: 
- predict with a significantly higher degree of reliability the condition of the facility, possible contingencies, respond quickly to them, reducing threats to safety, human health and the environment;

- increase the depth of understanding of the processes occurring in the object and the product, due to the accumulation of advanced statistics of "virtual" operation of objects;

- more accurately calculate the project economy and manage it;

- identify weak links and improve the design features of power units;

- reduce the time for implementation of the necessary changes.

Such opportunities forced to pay close attention to the technology of almost all the leading companies in the world, which ultimately brought the digital twin to the top ten strategic trends of 2020 .

\section{References}

Andriushchenko, K., Buriachenko, A., Rozhko, O., Lavruk, O., Skok, P., Hlushchenko, Y., Muzychka, Y., Slavina, N., Buchynska, O., \& Kondarevych, V. (2020). Peculiarities of sustainable development of enterprises in the context of digital transformation. Entrepreneurship and Sustainability Issues, 7(3), 2255-2270.

Andriushchenko, K., Datsii, O., Aleinikova, O., Abdulla, A. M., \& Ali, A. M. (2019). Improvement of the water resources management system at the territorial level. Problems and Perspectives in Management, 17(3), 421-437.

Andriushchenko, K., Kovtun, V., Shergina, L., Rozhko, O., \& Yefimenko L. (2020). Agro-based Clusters: A tool for effective management of regional development in the ERA of globalisation. TEM Journal., 9 (1), 198-204,

Andriushchenko, K., Lavruk, V., Uliganets, S., Kovtun, V., \& Matviienko H. (2019). Reputation risk management companies based on competence approach. TEM Journal, 8(2), 516-524.

Boschert, S., \& Rosen, R. (2018). Digital twin: A second life for engineering models. ERCIM NEWS, 115, 8-9.

Derby, E. (2017). Agile retrospective: How to turn a good team into a great team. Moscow: Publishing House of Dmitry. (In Russ.).

El Saddik, A. (2018). Digital twins: The convergence of multimedia technologies. IEEE multimedia, 25(2), 87-92.

Glaessgen, E., \& Stargel, D. (2012, April). The digital twin paradigm for future NASA and US Air Force vehicles. In 53rd AIAA/ASME/ASCE/AHS/ASC structures, structural dynamics and materials conference 20th AIAA/ASME/AHS adaptive structures conference 14th AIAA (p. 1818).

Kovtun, V., Andriushchenko, K., Horbova, N., Lavruk, O., \& Muzychka, Y.(2020). Features of the Management Process ofAmbidextrous Companies. TEM Journal, 9(1), 221-226.

Kupriyanovskii, V. P., Sinyagov, S. A., \& Dobrynin A. P. (2016). BIM - The Digital Economy. As have achieved success? A practical approach to the theoretical concept. Part 2. Digital economy. International Journal of Open Information Technologies, 4(3), 9-19. (In Russ.).

Lee, J., Bagheri, B., \& Kao, H. A. (2015). A cyber-physical systems architecture for industry 4.0-based manufacturing systems. Manufacturing Letters, 3, 18-23.

Podvoiskii, G. L. (2016). The Role of new technologies in the economy of the XXI century. Mir novoi ekonomiki= World of the new economy, 4, 6-15. (In Russ.).

Ponsard, C., De landtsheer, Renaud, \& Palm, B. (2018). Accurate Reasoning Using Imperfect Digital Twins: A Steel Industry Case Study. ERCIM NEWS, (115), 9-10.

Romanenko, Y. O., Chaplay, I. V. (2016). Marketing communication system within public administration mechanisms. Actual Problems of Economics, 178(4), 69-78.

Schwab, K. (2017). The Fourth industrial revolution. Translation from English. Moscow: Publishing House "Eksmo"; 2017.208 p. (In Russ.).

Strohmeier, F., Schranz, C., \& Guentner, G. (2018). I-maintenance: A Digital Twin for Smart Maintenance. ERCIM NEWS, 115, 1214.

Tao, F., Cheng, J., Qi, Q., Zhang, M., Zhang, H., \& Sui, F. (2018). Digital twin-driven product design, manufacturing and service with big data. The International Journal of Advanced Manufacturing Technology, 94(9-12), 3563-3576. (In Russ.).

Tolstykh, T. O., Dmitrieva, E. V., \& Lyadova, N. I. (2017, October). Priorities of digitalization in industrial enterprises of the region. In Proceedings of the 10th International scientific practice conference "State and municipal management in Russia: Experience, problems, prospects"(Voronezh, VF of the "Russian Academy of the National economy”, 27 October 2017). Preobrazhensky BG, ed. Voronezh: Publishing and printing center "Scientific book (pp. 200-207).

van Kruijsdijk, C. (2018). Digital Twins as R\&D Accelerators-The Case for an Open Source Ecosystem. ERCIM NEWS, (115), 14-15. Verriet, J., Sleuters, J., \& Doornbos, R. (2018). Using Digital Twins to Create and Manage Complex Distributed Control Systems.

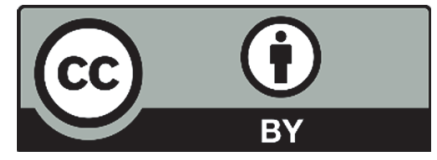

(C) 2020 by the authors; licensee Growing Science, Canada. This is an open access article distributed under the terms and conditions of the Creative Commons Attribution (CC-BY) license (http://creativecommons.org/licenses/by/4.0/). 